\title{
Robert F. Heary and Todd J. Albert: Spinal deformities: the essentials
}

\section{Thieme Verlag, New York, Stuttgart, 2007, HardCover 298 pp, number figures, Euro (D) 99.95 CHF 160.00, ISBN: 978-3-13-144121-8}

\author{
Pierre Kehr
}

Received: 28 February 2010/Accepted: 1 March 2010/Published online: 14 March 2010

(C) Springer-Verlag 2010

The surgery of the spinal deformations concentrates the whole of the problems with which can be confronted a specialized surgeon: difficult indications, wide fusion and its complications, morbidity and mortality important for a functional surgery. RF Heary and TJ Albert brought together in this book their colleagues of the other side of the Atlantic to expose their point of view on the complex problems raised by this surgery. And as opposed to what would imply the subtitle, it is not only the essence that is treated. This work goes well beyond basic knowledge, it carries out a modern and exhaustive panorama assumption of responsibility total of the spinal deformations. The work is divided into two parts: principles of spinal deformities and treatment of spinal deformities. The iconography, in black and white, is abundant.

This work is remarkable and must be recommended very highly. It will be considered regrettable that European authors were not invited to take part in this book, whereas they are at the origin of the modern surgical treatment of the spinal deformations.

Laurent Balabaud

Paris (France)

No funds were received in support of this study.
P. Kehr ( $\square)$

SOTEST, Strasbourg, France

e-mail: kehrpier@aol.com 